\title{
¿Cómo hablar mundanamente de Dios?
}

\section{How to speak worldly about God?}

\section{Como falar mundanamente de Deus?}

\author{
Mg. Antonio Freire Hermosilla ${ }^{1}$
}

Recibido: 15/03/2017 - Aceptado: 10/04/2017

\begin{abstract}
Resumen
La hegemonía de la racionalidad moderna ha llevado al vaciamiento y a la distorsión de nuestra relación con lo divino. No obstante, ese mismo agotamiento ha abierto otras vías para acercarnos a esa realidad. Consideramos que, desde nuestra propia contingencia, estamos en condiciones de retomar ese contacto.

Ya no es necesario acudir a las fórmulas religiosas tradicionales ni a las formas eruditas para nombrar a Dios. Desde esa perspectiva, nos proponemos retomar el meditar de Dietrich Bonhoeffer y valorar su búsqueda en el contexto que él percibió anticipadamente: un mundo secularizado.
\end{abstract}

Palabras clave: secularización - Dios - mundo - liturgia - misterio

\begin{abstract}
The hegemony of modern rationality has led to the emptying and distortion of our relationship with the Divine. However, this same exhaustion has opened other ways to approach that reality. We consider that, from our own contingency, we are in a position to resume that contact.

It is no longer necessary to go to traditional religious formulas or to the erudite ways of naming God. From this perspective, we propose to return to the meditation of Dietrich Bonhoeffer and to evaluate his search in the context he perceived in advance: a secularized world.
\end{abstract}

Keywords: Secularization - God - world - liturgy - mystery

1 Chileno. Magíster en Filosofía por la Universidad de Chile. Licenciado en Filosofía por la Universidad Pontificia Salesiana de Roma, Italia. Bachiller en Ciencias Religiosas por la Pontificia Universidad Católica de Chile. Académico de planta en la Escuela de Filosofía de la Universidad Católica Silva Henríquez. Contacto: afreireh@ucsh.cl 


\section{Resumo}

A hegemonia da racionalidade moderna tem levado ao esgotamento e a distorção da nossa relação com o divino. No entanto, o mesmo cansaço abriu outros caminhos para chegar mais perto dessa realidade. Consideramos que, a partir de nossa própria contingência, estamos em condições de retomar esse contato.

Já não é preciso ir para as fórmulas religiosas tradicionais ou formas eruditas para nomear a Deus. A partir dessa perspectiva, propomos retomar o meditar de Dietrich Bonhoeffer e valorar sua procura no contexto que ele percebeu antecipadamente: um mundo secularizado.

Palavras-chave: secularização - Deus - mundo - liturgia - mistério

\section{Introducción}

El giro lingüístico contemporáneo ha puesto como un punto de la discusión filosófica el habla y, junto con ella, el lenguaje y sus manifestaciones. No se trata de una reedición del logocentrismo, sino de una vuelta a la reflexión hablada y a la contemplación originaria. El exceso de racionalismo impuesto por el paradigma moderno ha significado una saturación de la metafísica y un agotamiento prematuro de la especulación idealista, pero ha abierto las puertas a la intuición y, con ella, a la percepción del misterio insondable e intangible. A través del habla tenemos acceso a lo sublime y trascendente. Postulamos que desde nuestra propia limitación, estamos en condiciones de nombrar lo innombrable, de acceder a lo inaccesible y de alcanzar lo inalcanzable.

Desde el punto de vista formal, ya no es necesario acudir a las estructuras clásicas que atestiguaban la validez de un lenguaje correcto sobre la divinidad. La mundanización de las realidades vitales ha permitido poner al alcance de todos lo que antes suponía un proceso de iniciación y de selección a partir de criterios ya establecidos. El desgaste de dichas estructuras las ha obligado a aceptar la diferencia y la validez de otros discursos más bien profanos y prosaicos.

El proceso de secularización instalado en la sociedad contemporánea da cuenta de este cambio estructural. No es la negación de lo sagrado, 
como paradigma de lo divino, lo que ha provocado el silencio de lo que nombra a Dios y su repliegue en otras esferas. Sin embargo, la incapacidad de hablar de Dios en un contexto mundanizado ha sido la preocupación de connotados autores en la contemporaneidad. Quizá uno que resulta más representativo de esta corriente ha sido el teólogo alemán Dietrich Bonhoeffer. En su caso no se trataba simplemente de una cuestión retórica. Su testimonio martirial supera ampliamente el carácter erudito de su preocupación por el tema. En efecto, cuando se está bajo la represión y la persecución política, como es el caso del teólogo alemán, su palabra cobra mayor relevancia y sobrepasa las contingencias histórico-temporales.

Recogemos el cuestionamiento de Bonhoeffer desde la filosofía, pues su planteamiento cruza las fronteras de la reflexión disciplinaria, se hace transversal y toca a otras áreas del pensamiento.

Nos proponemos partir con algunas consideraciones preliminares, analizar la visión de Bonhoeffer sobre el cristianismo arreligioso, revisar algunos léxicos que desde la religión condicionan y limitan nombrar mundanamente a Dios, para llegar a una lectura secularizada de la religión y, finalmente, sugerir los lugares desde donde es posible atender a las preguntas emblemáticas de Bonhoeffer: ¿cómo hablar de Dios mundanamente? y ¿dónde queda, pues, un sitio para Dios?

\section{Algunas consideraciones preliminares}

En torno a esta temática, el foco de atención de Bonhoeffer, propuesto en su epistolario escrito desde la cárcel, es eminentemente teológico-pastoral. Nuestro punto de partida, en cambio, es éticoreflexivo. Compartiendo la visión del teólogo alemán, no tenemos una suspicacia crítica con la religión, ni menos con la religión cristiana y católica en particular. De por sí, en el actual clima cultural, también nos encontramos con posturas radicalizadas a favor y en contra de la religión. Sin menospreciar ni caer en un afán de relativización, creemos que, para nuestro objetivo, confrontar ambas posiciones resultaría ocioso e innecesario. Más aún cuando, en el debate actual, 
las posiciones radicalizadas y los fundamentalismos fanatizados de cualquier tipo son vistos como una amenaza a la convivencia y a la integración humana.

En el libro de Bonhoeffer Resistencia y Sumisión (1983), el ámbito de la secularización-mundanización es algo más que un fenómeno que ha marcado el acontecer de la modernidad. Si bien en la época de la Reforma la secularización tenía ribetes estrictamente jurídicos, con el tiempo ha pasado a ser un estilo de vida que afecta a la humanidad en su globalidad. En efecto, influye en la forma de pensar, de valorar, de razonar, de sentir, en definitiva, de vivir. Algunas de sus expresiones son convergentes con la proclamación nietzscheana de la muerte de Dios, la caída de los metarrelatos de Lyotard, el anuncio poético de la huida de los dioses en Hölderlin, pero, sobre todo, con el abandono y el debilitamiento de la religión.

Más allá del importante papel que la religión ha desarrollado permanentemente en la historia de la humanidad, da la impresión que, como cualquier estructura cultural, su agotamiento y debilitamiento es indesmentible. En esto coincidimos con el análisis realizado por Bonhoeffer, quien sostiene que la religión "ha sido una forma de expresión del hombre históricamente condicionada y transitoria", y que "ha pasado asimismo el tiempo de la interioridad y de la conciencia; es decir, justamente el tiempo de la religión en general" (Bonhoeffer 197).

Desde esta perspectiva, la secularización, si bien comporta elementos de desacralización, ha devenido en mundanización. Por lo demás el término latino "saeculum" se traduce al castellano como "siglo" y, también, como "mundo". Una lectura pietista, indudablemente, abomina y rechaza el mundo, pues lo considera como un principio de perdición y de descomposición. Sin embargo, el término puede interpretarse en cuanto tal como el antónimo de lo "inmundo": expresión claramente abyecta y despreciable. Una mirada metafísica puede privilegiar, a su vez, el ámbito de lo "espiritual", de lo "sublime" en oposición a lo "mundano". Tratando de limitar ese tipo de distinciones y de discusiones, daremos al término "mundo" un 
alcance netamente lexicológico y cultural: mundo como espacio de convivencia y convergencia humana.

Hacemos notar que esta concepción de "mundo" está en sintonía con el "habitar" heideggeriano, que se vincula directamente con el "Ethos" o morada del hombre. De ahí que nuestra reflexión adquiera un tono ético.

Por otra parte, entendemos que la expresión "cristianismo arreligioso" (Bonhoeffer 1983 197) utilizada por Bonhoeffer tampoco constituye un ataque artero y destemplado contra el cristianismo. La fórmula que utiliza no destruye el carácter eclesial y comunitario propio del cristianismo. Un "cristianismo arreligioso" no quiere decir que el cristianismo sea ajeno a la Iglesia, a la religión, o carezca de vida comunitaria, como lo afirma en otras de sus obras. ${ }^{2}$ Si bien el mismo contexto histórico en el que escribe Resistencia y Sumisión revela un clima hostil y de persecución para la Iglesia luterana alemana que se levantó contra la tiranía nazista, es legítimo pensar que él tuviera una preocupación por proteger la Iglesia y salvaguardar su mensaje y su vida. Algo semejante ocurre hoy, pues, más allá de un hostigamiento sistemático a la Iglesia católica, en nuestro caso hay un abierto y suspicaz cuestionamiento de su poder temporal. ${ }^{3}$

2 Una de estas obras es Vida en comunidad. Salamanca, España: Ediciones Sígueme, 1999, y la otra es El precio de la gracia. Salamanca, España: Ediciones Sígueme, 1995.

3 Aunque el objetivo de este trabajo no es de carácter apologético, eso no quita que nos detengamos en este punto para hacer algunos comentarios. Nos interesa relevar la autonomía de la institución eclesial, y por eso no es conveniente polemizar, ni mucho menos dirigir ataques destemplados contra ella. De por sí existe un ámbito de dominio y soberanía que no menoscaba la autoridad eclesial. El dominio no puede estar asociado necesariamente con el poder y con el control. En principio "dominio" deriva de "dominus" ("señor", "soberano") y, en este caso, apunta directamente al señorío y a la soberanía de la institución. Por eso, el ejercicio de la soberanía implica más bien un cuidado por aquello sobre lo que se tiene dominio. Justamente este dominio, en cuanto cuidado, implica una protección, una liberación y no un castigo o un control persecutorio, extorsionador y subyugante. El dominio en este sentido significa promover, cuidar y respetar la autonomía de aquellos que adscriben a una fe religiosa. Allí se manifiesta propiamente el dominio y la soberanía. 


\section{Hacia una compresión de la expresión "cristianismo arreligioso" de Bonhoeffer}

Como ya hemos planteado, sería injusto atribuir a las palabras de Bonhoeffer un carácter destructivo y descalificador del cristianismo. Asimismo, no sería correcto atribuirle un carácter apologético a sus afirmaciones en torno a la espiritualidad y a la vivencia del cristianismo de su época.

Cuando manifiesta su vergüenza de nombrar a Dios ante los religiosos, lo hace "porque en ese contexto su nombre me parece que adquiere un sonido casi ficticio y yo tengo la impresión de ser algo insincero" (Bonhoeffer 1983 198). Se trata de una sensación que afecta justamente su manera de concebir y nombrar a Dios. Esta especie de molestia e insatisfacción revela una búsqueda que está por encima de las vías tradicionales y desgastadas de la reflexión metafísica. Se impone, pues, incursionar en nuevos caminos que orienten la búsqueda sincera y auténtica de aquello que nombra a Dios.

Como él lo manifiesta, se trata de, "nombrar a Dios con toda tranquilidad y como algo obvio" (Bonhoeffer 1983 198), como lo hace ante los no religiosos cuando hay ocasión de hacerlo. Por tanto se abre una alternativa que motiva a arriesgarse y a hacer el intento de nombrar a Dios fuera del esquema religioso. En consecuencia, es preciso reconocer que, también, la estructura propiamente mundana, ajena al ámbito religioso, permite nombrar a Dios de manera sincera y abierta. Libre de prejuicios, el vocablo Dios adquiere más resonancia y autoridad.

\section{Algunos léxicos utilizados en la religión que condicionan y limitan nombrar mundanamente a Dios}

Como hemos visto, a Bonhoeffer, en su experiencia personal, le resulta particularmente grave cuando se comienza a hablar con terminologías religiosas; "entonces enmudezco casi por completo y el ambiente me resulta pegajoso y molesto" (Bonhoeffer 1983 198). Es cierto que, siendo válidos los conceptos religiosos, en un clima de secularización 
aparecen como algo obsoleto, atemporal y añejo. A menudo estos conceptos carecen del carácter significativo y vivencial respecto de las expresiones de uso coloquial y profano. Aún más, pueden aparecer como algo extraño y extemporáneo.

Nos surge la inquietud: en un mundo sin religión, ¿qué se entiende por pecado, penitencia, ayuno, catequesis, sacramentos, milagro, ascensión, culpa, redención? Frente a ello Bonhoeffer también se pregunta: "¿Cómo hablar de Dios sin religión, esto es, sin las premisas temporalmente condicionadas de la metafísica, de la interioridad, etc.?" (Bonhoeffer 1983 198).

Nuestro autor interpreta el uso frecuente de la terminología religiosa tradicional como reflejo de una simple pereza mental o un fracaso de las fuerzas humanas. Pensamos que este tipo de actitud refleja, además, una conducta que infantiliza el comportamiento y el entendimiento de los creyentes en un credo religioso. Por comodidad se reduce a Dios a un "deus ex machina", a un "dios tapa-hoyos", que resolvería problemas insolubles y que, por consiguiente, estaría siempre sacando partido de la debilidad y de las limitaciones humanas.

Por lo demás, en la cultura contemporánea, la imagen de un "deus ex machina" resulta cada vez más superflua e intrascendente. Si bien la ciencia y la técnica actuales mantienen ciertos límites, nada ni nadie les impide seguir avanzando. Por lo demás, hablar de Dios en términos de omnipotencia pondría en riesgo su dignidad, pues lo expondría a competir $y$, eventualmente, perder frente a estructuras contingentes ajenas a la condición divina. Muchos de los problemas humanos que antes resolvía Dios, hoy los resuelven con mayor precisión y exactitud la ciencia y la técnica. Sin embargo, esto no suprime la acción divina ya que esta no se restringe a resolver problemas insolubles ni a desnudar las flaquezas humanas.

Otro pensador procedente del ámbito de la teología comparte esta visión positiva de la secularización. Edward Schillebeeckx, teólogo belga, considera que la secularización y la ausencia de Dios en la actividad de los hombres son una ganancia. Él estima que éstas serían la manifestación de la madurez del hombre contemporáneo. Al despojarse 
de las funciones de suplencia de la religión, afirma Schillebeeckx, el hombre descubre su ser más auténtico y Dios pasa a ser una hipótesis inútil; luego, para hallar su camino en el mundo, el hombre no tiene necesidad de Dios. A esta altura de la historia, la humanidad puede muy bien arreglarse sin Dios ${ }^{4}$ (Schillebeeckx 1965 76).

\section{Hacia una lectura secularizada de la religión}

Como podemos ver, no se trata de precarizar ni minimizar el aporte con que las religiones han ayudado en la configuración del mundo y de la historia. Más bien, en su estructura formal podemos descubrir aspectos que nos pueden ayudar a conseguir nuestros objetivos: hablar mundanamente de Dios y encontrar un sitio para Él.

Sin realizar un análisis exhaustivo de la religión, podemos señalar que, básicamente, esta incluye, al menos, tres áreas: el dogma, la moral y el culto. Toda religión posee un cuerpo de doctrinas reveladas que forman parte del depósito de la fe y tienen el carácter de fundamento. Las afirmaciones de fe son propias de cada religión y le otorgan un principio de unidad y de coherencia. La moral viene a ser un despliegue del aspecto doctrinal aplicado a la vida personal y comunitaria de quienes forman parte de la asamblea de creyentes. A partir de ella, gran parte de las sociedades la han instituido como un elemento de cohesión e integración social. También, la pertenencia a una cultura muchas veces incluía la observancia de normas y principios morales compartidos. Por último, podemos afirmar que el culto es la forma exterior de celebrar la fe y los principios que guían las costumbres y comportamientos. Sus manifestaciones son rituales y, en gran parte, sirven para renovar y revivir la doctrina de la fe y los ideales de una vida moral compartida.

4 Conste que no nos estamos refiriendo al ateísmo y al agnosticismo, posturas muy respetables, pero que a esta altura de la discusión no tendrían cabida. Lo que ponemos en discusión no es la existencia o eventual aceptación de Dios, sino pesquisar las condiciones de posibilidad para hablar sobre él mundanamente y encontrarle un sitio en este mundo. 
Pensamos que la manifestación secularizada de uno de estos elementos constitutivos de la religión nos permitiría acercarnos a un lenguaje con el que podamos nombrar a Dios mundanamente. El dogma y la moral están asociados de manera directa con la identidad y la naturaleza de cada religión en particular, por tanto no sería apropiado realizar un acercamiento a nuestro objetivo mediante ellas. Sin embargo, hay más elementos imparciales y neutros en el culto que sintetizan una sensibilidad compartida. En el mundo contemporáneo esta dimensión adquiere alcances planetarios y, a causa de la globalización, sobrepasa los límites geográficos y culturales. Algunos suelen ver en algunas celebraciones colectivas y masivas, manifestaciones paganizadas de ritos religiosos ancestrales: es el caso del "carnaval" y de la "navidad", por ejemplo.

\section{Lugares mundanos desde los que es posible instalar el discurso sobre Dios: la liturgia en clave profana, el misterio, el sentimiento y la pasión, la razón cordial, la serenidad y la ausencia}

\subsection{La liturgia en clave profana}

En general, el culto al interior de la religión se nombra como liturgia y celebración del misterio. En su libro Opus Dei, Giorgio Agamben procura "rescatar el misterio litúrgico de la oscuridad y vaguedad de la literatura moderna del tema" (Agamben 14).

De partida puntualiza que el vocablo "liturgia" deriva del griego "Leitourgía" (de laos, pueblo y érgon, obra). Podemos deducir que su sentido originario no es sagrado ni religioso, sino laico y político. La liturgia, en principio, se refiere a "la obligación de dar una serie de prestaciones de interés común" (Agamben 19), por tanto de carácter político. Aún más, señala Agamben, Aristóteles habla de liturgia en el sentido de un "servicio público para la procreación de los hijos". Apunta que también en las cartas paulinas el término tiene un significado profano de "servicio a la comunidad" (Id. 24). 
Ya en su libro El Reino y la Gloria Agamben había indagado en el misterio litúrgico. En cambio en Opus Dei su investigación la orienta hacia el "ministerio del misterio". Para él, el misterio de la liturgia es el misterio de la efectualidad, que hace posible entender "la enorme influencia que esta praxis ejerció sobre el modo como la modernidad pensó tanto su ontología como su ética, su política como su economía" (Agamben 14).

Cabe señalar previamente que el vocablo "liturgia" es relativamente moderno y que hacia finales del siglo XIX aparece en su lugar el término latino "officium" (Agamben 13). Para Agamben este último ha ejercido una influencia profunda en la cultura moderna, no solo en la conceptualización de la ética kantiana y en la teoría pura del derecho de Kelsen, sino también en la convivencia social contemporánea; el militante político y el funcionario burocrático se inspiran en el mismo paradigma. Su influjo cultural afectó aun a las categorías de la ontología y de la praxis. En el ámbito del pensamiento filosófico, el paradigma ontológico ha quedado definido por la operatividad y la efectualidad. En este sentido, sostiene Agamben, la invención de los oficios cambió tanto las reglas de la metafísica como las de la ética (Id. 15). El traspaso de sentido del oficio de lo santo a lo profano adquirió ribetes significativos en la vida político-social. En el mundo contemporáneo lo que vale o se valora es lo que tiene un alcance concreto, es decir, lo que interesa o importa en forma directa a los participantes en la vida en sociedad. Es aquí donde se abre un espacio a lo divino en la medida que no se pierda de vista lo que concita la atención de los hombres. Hablar de Dios no parece algo extraño cuando se vincula con lo contingente y lo significativo para el hombre de hoy. No se trata de una concesión magnánima por parte de Dios, más bien es una oportunidad gratuita y desinteresada que concede el mundo.

Otra veta de la reflexión litúrgica que nos propone Agamben para trabajar es la obra de un monje alemán de principios del siglo veinte llamado Odo Casel. Coincidentemente con nuestras apreciaciones, Agamben cita un texto de Casel que dice:

El cristianismo no es solo una "religión" o una "confesión" en el sentido moderno de esos términos, es decir, un sis- 
tema de verdades establecidas más o menos dogmáticamente que se aceptan y se profesan, o bien un conjunto de imperativos morales que se observan o por lo menos se reconocen. El cristianismo es, por cierto, todo esto; es tanto un conjunto de verdades como una ley moral. Pero ello no agota su esencia (1966).

\subsection{El misterio como acción litúrgica}

Para Agamben la tesis que resume el pensamiento de Casel se puede sintetizar en la siguiente fórmula: el cristianismo es esencialmente misterio, es decir, una acción litúrgica. Por ello, Casel emprende la reivindicación del misterio justamente en contra de la desacralización y la racionalidad del mundo que caracteriza a la edad moderna (Agamben 57).

En el pensamiento de Casel, plantea Agamben, la liturgia prevalece por encima de la doctrina; tal como ocurre en los movimientos políticos contemporáneos, la praxis está por encima de la teoría. Esta realidad podría representar un peligro en la medida en que la política descuide las ideas y se dedique casi exclusivamente a cuestiones urgentes que surjan de la contingencia concreta. De hecho, esta es, sin duda, la situación por la que atravesamos. No hay espacio para lo sublime ni para lo trascendente. Nuestra preocupación está en lo inmediato y es precisamente allí donde concentramos nuestra atención. Esta cultura de la inmediatez afecta, sobre todo, el área política. Por lo general vemos que en los partidos políticos no hay interés ni esfuerzo por fortalecer el aspecto ideológico y doctrinal. Más bien pesa la preocupación por lo momentáneo y circunstancial. A su vez, esta actitud se proyecta en la vida social y familiar: interesa lo inmediato $y$, curiosamente, se valora lo efímero e intrascendente. En un mundo desacralizado, pena la ausencia de lo sagrado. Y, sin embargo, este sería el lugar para hablar mundanamente de Dios.

Reconocemos que la liturgia y el culto tienen una expresión genuina al interior de la religión; no obstante, hoy en día también se hacen presente en la sociedad con un fuerte sello mundano. Hemos advertido la paganización de celebraciones religiosas. Sin embargo, el carácter 
ritual y celebrativo va más allá de las manifestaciones protocolares del quehacer político-social. La misma farándula está marcada por lo festivo y lo ritual. Podría parecer contraproducente, pero es allí donde se puede encontrar un sitio para buscar y nombrar a Dios. En efecto, ya en la antigüedad los dioses se hacían presente y presidían las fiestas y celebraciones populares. Algo semejante ocurría en las peregrinaciones medievales y en las fiestas patronales de la cristiandad. Un celo puritano ha pretendido separar el ámbito santo y sagrado del ámbito profano y mundano, produciendo una escisión y un alejamiento de los participantes en dichos rituales. Se genera, efectivamente, un recelo y un distanciamiento de la religión. Sin embargo, el fervor y el entusiasmo se mantienen aunque de manera oculta. De hecho, muchas expresiones que se despliegan en celebraciones profanas, se inspiran en los rituales ancestrales de cuño religioso.

\subsection{El sentimiento, la pasión}

Hablar de Dios desde el sentimiento no resultaría ficticio ni falto de sinceridad, sería fundamentalmente legítimo y auténtico, ya que no se daría lo que Boff llama la "hegemonía del Logos" sino la emergencia del Pathos. En los festejos masivos, habría más bien una apelación al sentimiento y a la pasión, al desborde de las emociones, al delirio de las pulsiones, al éxtasis orgiástico del placer (Boff 1982). El pensador brasileño afirma que cuando la razón impone su dominio, surge la rigidez, la inflexibilidad, la tiranía de la norma, la dominación del orden, el rigor de la disciplina. En cambio, cuando aflora la fuerza del sentimiento, emerge la ternura y el cuidado, que él califica como algo bien distinto al sentimentalismo. Para Boff, la ternura y el cuidado se asocian al espíritu de fineza pascaliano, al ámbito de la cordialidad. Allí se dan condiciones de posibilidad para situar a Dios y desplegar un discurso sobre su esencia y realidad. Boff subraya que el corazón es el órgano del espíritu de fineza; desde allí se produce la cordialidad como expresión de la ternura y el cuidado. El corazón, en cuanto expresión del sentimiento, no se opone al intelecto, sino que "es la capacidad del espíritu de captar el carácter axiológico del ser, su fascinación y su brillo" (Boff 2012). 
Desde esta perspectiva, sostiene Boff, la razón no irrumpe como la realidad primera. Antes de ella hay un universo de pasiones y emociones que mueven al ser humano. Por encima de la razón hay inteligencia por la cual intuimos la totalidad, el infinito y el éxtasis de la contemplación del ser. La razón es la razón de la sin razón. Es un misterio que demanda ser descifrado. La Razón Pura kantiana, afirma el pensador brasileño, es una ilusión, ya que siempre viene impregnada de emoción y de pasión. Aun el ámbito del conocimiento está marcado por la comunión interesada y afectiva. "Conocer" en francés se dice connaître que significa "nacer con la cosa". Y en castellano, "concepto", en cuanto resultado del conocimiento, significa "algo que fue concebido en la relación sujeto-objeto" (Boff 2012).

\subsection{La razón cordial}

De acuerdo con Boff, la característica esencial del ser humano no reside en el cogito cartesiano (en el yo pienso, luego existo) sino en el sentio (en el siento, luego existo) en el sentimiento profundo (Boff 2012). Son las pasiones, los sentimientos fuertes, la amistad y también sus contrarios los que nos mueven y nos ponen en marcha, nos levantan, nos hacen enfrentar los peligros, atravesar abismos y jugar con la propia vida. En la razón cordial, sensible y emocional es posible hablar de Dios sin complejos ni temores. El pensamiento occidental, logocéntrico y antropocéntrico, relegó el sentimiento a un lugar secundario. Tal exceso de racionalismo, nos dice Boff, llegó a producir una completa insensibilidad. Y este mismo exceso de autosuficiencia puso en entredicho al misterio considerándolo como un elemento nocivo e irrelevante para la sociedad moderna. El misterio se entiende con la razón cordial, el misterio recrea el lugar para invocar a Dios y nombrarlo con propiedad.

Según Agamben, el cambio litúrgico promovido por Casel surgió como "reacción contra el individualismo humanista y la racionalización del mundo que define a muchos movimientos que aparecen tras la primera guerra mundial" (Agamben 60). Estas posturas pretendían disipar la oscuridad del misterio y recuperar su energía y vitalidad. 
Efectivamente, el colapso de estas posiciones, por el contrario, reabrió "la vía del retorno al misterio" (Casel 30). El mundo volvió a ser el lugar donde reaparece el misterio. Casel constata que también el mundo ajeno al cristianismo y a la Iglesia está hoy en la búsqueda del misterio. De hecho, el culto cristiano deriva del misterio pagano y lo valora como un camino adecuado para acercarse y hablar de Él.

\subsection{La serenidad}

Otro gran pensador contemporáneo que busca reivindicar lo que él llama la "serenidad" y la "apertura al misterio" es Martín Heidegger, que propone el "pensamiento meditativo" como una alternativa al "pensamiento calculador", propio de la ciencia y de la técnica moderna y expresión emblemática del racionalismo moderno y de la hegemonía del logocentrismo (Heidegger 19). En el mundo técnico, el sentido se aparta y se oculta en la medida en que viene hacia nosotros, a nuestro encuentro. Lo que al mismo tiempo se muestra y se retira es el rasgo fundamental de lo que Heidegger llama "misterio". Heidegger nombra "la actitud por las que nos mantenemos abiertos al sentido oculto del mundo técnico la apertura al misterio" (Id. 29). Junto con la serenidad, la apertura al misterio es otra actitud adecuada para enfrentar lo avasallante de la cultura técnica contemporánea. Ellas nos permiten habitar en el mundo de un modo muy distinto, "nos abren la perspectiva hacia un nuevo arraigo". Estas actitudes, advierte el pensador del ser, no nos caen del cielo fortuitamente, sino que brotan de un pensar incesante y vigoroso, no calculador sino meditativo. Ciertamente los caminos de la reflexión, en la medida en que se abren al misterio, pueden constituirse en un espacio secular y mundano desde donde emprender la tarea de nombrar a Dios con sentido y serenidad.

Asociado a su concepción del misterio, Bonhoeffer se pregunta ¿dónde queda un sitio para Dios? (Bonhoeffer 1983 252). No concibe el misterio como algo periférico y extraño y no lo sitúa en los límites sino en el centro, prefiere hablar mundanamente de Dios "no en las debilidades, sino en la fuerza, no a la hora de la muerte y de la culpa, 
sino en la vida y en lo bueno del hombre" (Id. 198-199). En el caso de los límites, le parece mejor guardar silencio y dejar sin solución lo insoluble.

En cuanto habitantes de este mundo, no estamos en los límites, sino en el centro de la aldea. Desde ahí constatamos que el mundo se encamina hacia su autonomía. En un mundo secularizado se sostiene la suficiencia de la razón en el plano del conocimiento; se establecen reglas de vida en el lugar de los mandamientos; la política se independiza de la moral en general y se funda la doctrina de la razón de Estado. En general, en el ámbito de la filosofía, la autonomía del hombre y del mundo constituye la meta de la reflexión. La autonomía de la sociedad erige su derecho natural como un derecho de gentes, válido etsi Deus non daretur (incluso si Dios no se diera).

Efectivamente hemos de vivir en el mundo etsi Deus non daretur. Ya para Descartes, reconoce Bonhoeffer, el mundo es un mecanismo que funciona por sí solo, sin la intervención de Dios. Para Descartes, paradójicamente, es el mismo Dios quien nos obliga a ese reconocimiento, que nos hace saber que hemos de vivir como hombres que logran vivir sin Dios. En definitiva, concluye Bonhoeffer, "ante Dios y con Dios vivimos sin Dios" (Bonhoeffer 1983 252).

\subsection{La ausencia}

El hombre contemporáneo debe vivir en el mundo sin Dios, y si debe vivir "mundanamente" no le es lícito intentar escamotear, transfigurar religiosamente su carencia de Dios. La edad adulta del mundo, lograda a través del proceso de secularización, al eliminar una falsa imagen de Dios, libera la mirada religiosa del hombre hacia Dios, que adquiere un lugar en el mundo gracias a su impotencia. Allí entra en juego la "interpretación mundana" de Dios y se hace posible hablar sobre Él con toda tranquilidad y como algo obvio: tal es el deseo y la intención del teólogo alemán. De acuerdo con el análisis de Bonhoeffer, al estar liberado de las falsas vinculaciones e inhibiciones religiosas, el hombre de nuestro tiempo puede vivir y hablar "mundanamente" de Dios. 
La ausencia de Dios en la cultura contemporánea no es un mero fenómeno. Casi podría afirmarse que es una necesidad ontológica. Aquello que nombra a Dios no pertenece al ámbito de lo divino, que es precisamente un lugar donde no habitamos los mortales. Lo que está a nuestro alcance es el mundo y sus vicisitudes. Desde allí es de donde podemos nombrar aún lo lejano y lo ausente, lo infinito y lo eterno. Si nos cerramos a la posibilidad de nombrar a Dios mundanamente, deberíamos abordar otra esfera de conocimiento y existencia. Esto significaría renunciar a nuestra condición humana y vivir enajenados.

\section{Conclusiones}

Junto con reivindicar el cuidado por hablar de Dios mundanamente, nos asiste la preocupación de retomar la otra pregunta de Bonhoeffer: ¿dónde queda pues un sitio para Dios?

El mundo contiene variadas expresiones y espacios de convivencia. El mundo no se agota en una sola dimensión. El mundo va más allá de un cosmos ordenado, ya que posee variadas facetas muchas veces contrarias y contradictorias entre sí. En él podemos encontrar lo más sublime y lo más abyecto. En el mundo caben todas las posibilidades y las capacidades humanas. Junto a la fanfarria y la algarabía aparecen el silencio y el recogimiento, lo calculador y lo meditativo, lo mistérico y lo profano. El mundo no es un espacio escindido de la realidad; lo que en él acontece no es ajeno a su estructura. El mundo es un dato, un don que funciona autónomamente. Aquí también hay un sitio gratuito para Dios.

A su vez, las opiniones de autores de diversas proveniencias, disciplinas y culturas nos han permitido reabrir el debate y nos han condicionado a no encerrarnos en posiciones dogmáticas e intransigentes. Además nos han persuadido de no dictar cátedra ni sermones paternalistas sobre el tema.

Frente al misterio divino solo podemos esgrimir nuestra inferioridad y fragilidad. Sin embargo, con esto no se cierra la puerta para que al 
menos podamos balbucear el nombre de Dios desde nuestra flaqueza y debilidad. Un sitio para Dios se genera desde donde se hace posible hablar sobre Él. Podemos establecer como lugares desde donde hablar mundanamente y en donde fijar la soberanía divina aquellos que hemos descubierto a lo largo de nuestra reflexión: la liturgia en clave profana, el misterio, el sentimiento y la pasión, la razón cordial, la serenidad y la ausencia.

De todas maneras, pareciera que en nuestra época carecemos de palabras que nombren auténticamente a Dios. Las que utilizamos están fuera del ámbito trascendente y más bien representan un decir mundano, ateo e impío. Pero, como nos advierte Schillebeeckx, mientras continúe la historia, todo concepto de Dios será inadecuado y de la misma manera lo será nuestro actual "silencio acerca de Dios" (1971 79). Sin embargo, esta misma experiencia secularizada contiene elementos que nos orientan hacia el misterio insondable e intangible. De hecho, si nuestra esencia humana consiste en existir en la manera de comprendernos, podremos únicamente nombrar a Dios cuando esa palabra esté vinculada con nuestra propia compresión mundana. En la cultura de la secularización, vigente hoy en día, no podríamos nombrar a Dios si no lo hiciéremos mundanamente.

Siendo así, podemos concluir que, desde nuestra propia limitación, estamos en condiciones de nombrar lo innombrable, de acceder a lo inaccesible y de alcanzar lo inalcanzable.

\section{Bibliografía}

Agamben, Giorgio. Opus Dei. Arqueología del oficio. Valencia: Pre-textos, 2013.

Boff, Leonardo. San Francisco de Asís. Ternura y vigor. Santander: Sal Terrae, 1982.

Boff, Leonardo. O cuidado necessário. Petrópolis: Editora Vozes, 2012.

Bonhoeffer, Dietrich. Resistencia y sumisión. Salamanca: Ediciones Sígueme, 1983.

Bonhoeffer, Dietrich. Vida en comunidad. Salamanca: Ediciones Sígueme, 1999. 
Bonhoeffer, Dietrich. El precio de la gracia. Salamanca: Ediciones Sígueme, 1995.

Casel, Odo. Il mistero del culto cristiano. Torino: Edizioni Borla, 1966.

Heidegger, Martín. Serenidad. Barcelona: Ediciones del Serbal, 2002.

Schillebeeckx, Edward. Dios y el hombre. Salamanca: Ediciones Sígueme, 1965.

Schillebeeckx, Edward. Dios futuro del hombre. Salamanca: Ediciones Sígueme, 1971. 